\title{
Antihistaminic Induced Febrile Seizure - An Important association: a Case report
}

\author{
Patel $\mathbf{U}^{1}$, Patel $\mathbf{N}^{2}$, Jain $\mathbf{R}^{3}$, Ratre $\mathbf{B}^{4}$ \\ ${ }^{1}$ Dr Umesh Patel, Associate Professor in Pediatrics, ${ }^{2}$ Dr Narmada Patel, Assistant Professor in Medicine, ${ }^{3}$ Dr Roopesh Jain, \\ Associate Professor in Anesthesiology, ${ }^{4}$ Dr Bhupendra Ratre, Associate Professor in Medicine. All are affiliated with L N \\ Medical College, Bhopal (MP), India
}

Address of Corresponding Author: Dr Umesh Patel, Email: drumeshpatel@ gmail.com.

\begin{abstract}
The histamine H1 receptor antagonist (antihistamines) are an important class of commonly used medications for the relief of symptoms associated with common cough and cold occurring in children. We report two cases of antihistaminic induced febrile seizure in children below five year. We consider importance of reporting such cases in view of their common usage and propensity to provoke seizure in susceptible children.
\end{abstract}

Keywords: antihistamine, histamine $\mathrm{H} 1$ antagonist, febrile seizures.

\section{Introduction}

Febrile convulsions are the commonest provoked seizures in childhood, occurring in 3-5\% of children younger than 5 years of age ${ }^{1}$. They are defined as seizures during fever occurring between 6 months to 5 years of age, in the absence of infection of central nervous system in a neurologically normal child. The peak age of onset is approximately 14-18 months. A strong family history of febrile convulsions in siblings and parents suggests a genetic predisposition ${ }^{2}$.

The pathogenesis of febrile convulsions is not clear even today. Viral infections of the upper airways, acute otitis media, infection of the urinary tract, and febrile reactions

Manuscript received: $13^{\text {th }}$ Sep 2013

Reviewed: $26^{\text {th }}$ Sep 2013

Author Corrected: $9^{\text {th }}$ Oct 2013

Accepted for Publication: $20^{\text {th }}$ Oct 2013 after vaccination are the most frequent precipitating factors ${ }^{3}$.

There is some case reports describing the association antihistaminic and febrile seizures in susceptible children. It has been demonstrated that increased histamine levels elevate the seizure threshold and reduce the severity and duration of seizures ${ }^{4}$, whereas decreased histamine levels have the opposite effect ${ }^{5}$. Of the four histamine receptors, the histamine-1 (H1) and histamine-3 (H3) receptors are suggested to be of importance in decreasing seizure activity. The first-generation $\mathrm{H} 1$ receptor antagonists, such as schlorpheniramine elicit epileptiform activity ${ }^{6}$.

Seizures have been very well reported in the literature with some first-generation antihistamines 
(chlorpheniramine, diphenhydramine, pheniramine, and pyribenzamine) as well as with some of the newer generation antihistaminic (astemizole, cetirizine, fexofenadine, loratadine, and terfenadine $e^{7,8}$.

\section{Case Report}

Case 1: A four years old male child of a doctor couple presented in emergency department with history of one episode of vomiting followed by sudden onset of uprolling of eye balls, clinching of teeth, frothing and unconsciousness for few seconds followed by drowsiness for few minutes while returning back from school in school bus. His seizure episode was documented by the teacher in the bus. There was no history of fever. Patient had only mild common cold for which only cold remedy containg chlorpheneramine was given in the morning.

There was no history of febrile seizure or any neurological disorder to the patient or first or second degree of relatives. In the emergency department child was conscious, oriented and having fever $104{ }^{0} \mathrm{~F}$.

Neurological examination was normal except equivocal planters; pupils were normal in size and reacting to light. All basic investigations were within normal limit. Total leukocyte counts was $8700 / \mathrm{mm}^{3}$, CRP-Negative, Serum Na-142 mEq/L, Serum K- 4.2 MEq/L, Random blood sugar- $98 \mathrm{mg} \%$, Serum Ca-9.2 mg \% . MRI brain was also normal. Final diagnosis for this child was Simple febrile seizure.

Case 2: After 2 days of above mentioned kid getting discharged from hospital his younger brother of 9 month who had mild cold and fever, had a similar episode of clinching of teeth, generalized tonic clonic seizure and unconsciousness for few seconds followed by drowsiness for few minutes which was observed by his father and was brought to hospital. This kid was treated symptomatically and was discharged same day after observation of few hours. When the detailed history was taken, parents revealed history of the usage of same cold remedy containing chlorpheneramine in morning. Final clinical diagnosis was was febrile seizure.

Hence we assume that this particular antihistaminic drug was responsible for precipitating febrile seizure in both the siblings.

\section{Discussion}

Antihistamines are widely used drug in the community for intercurrent common cold of childhood. The two cases which we reported here is for the purpose of spreading awareness in the medical community regarding potential of antihistaminic to lower the seizure threshold and their association with the occurrence of febrile seizure. Both of our patient were less than 5 years and both of them received the same antihistaminic agent; Chlorpheramine which might be responsible for the febrile seizure in both the patients. Both patients recovered with conservative measures and were not started on any long term antiepileptic drugs.

Many studies conducted recently shows that time from fever detection to seizure onset was significantly shorter in antihistamine groups compared with the nonantihistamine group ${ }^{2}$. Seizure duration was also significantly longer in the first-generation antihistamine group than in the non-antihistamine group.

Kiviranta et $\mathrm{al}^{9}$ evaluated the possible role of histamine in the pathological mechanism of febrile seizures by measuring histamine concentrations in the cerebrospinal fluid. Febrile children without seizures had a significantly higher histamine concentration than children with febrile seizures, while nonfebrile children with seizures and without seizures had similar histamine concentrations.

Churchill JA and Gammn GD ${ }^{10}$ also found in their study that use of histamine $\mathrm{H} 1$ antagonists was significantly higher in patients with febrile seizures than in the 
controls. Miyata et $\mathrm{al}^{11}$ reported in clinical observation that clinical doses of histamine $\mathrm{H} 1$ antagonists have the potential to modify seizures adversely in children. Two other recent studies Tankano T et al $(2010)^{12} \&$ Kulkarni R (2010) ${ }^{(13)}$ also reported that time from fever detection to seizure onset was significantly shorter in the antihistamine group than that in the nonantihistamine group, and that seizure duration was significantly longer in the antihistamine group than that in the nonantihistamine group.

\section{Conclusion}

Due to their central nervous system effects on decreasing seizure threshold, H1 antagonists should not be administered to patients with history febrile seizures and epilepsy. Caution should also be exercised regarding the use of histamine $\mathrm{H} 1$ antagonists in infants and children below five year because these drugs could potentially disturb the anticonvulsive central histaminergic system and hence precipitate febrile seizures in genetically predisposed patients. Since both of our patients were from same family an element of genetic predisposition may exist in them. These cases are reported to spread awareness and execute caution while prescribing antihistamic drugs to children below five years.

\section{Disclosure}

No benefits in any form have been received or will be received from any commercial party related directly or indirectly to the subject of this article.

\section{Funding: Nil}

\section{Conflict of interest: Nil}

Permission from IRB: Yes

\section{References}

1. Duffner PK, Baumann RJ. A synopsis of the American Academy of Pediatrics' practice parameters on the evaluation and treatment of children with febrile seizures. Pediatr Rev. 1999 Aug;20(8):285-87.

2. Kliegman RM, Stanton BF, Gemelll JW, Schor NF, Behrman RE. Nelson's Textbook of Pediatrics. 18th ed. New York: Elsevier; 2007.p 1994

3. Gubser M, Blumberg A, Donati F. Febrile convulsions: assessment of current status. Schweiz Med Wochenschr. 1999 May ;129(17):649-57.

4. Yawata I, Tanaka K, Nakagawa Y, Watanabe Y, Murashima YL, Nakano K. Role of histaminergic neurons in development of epileptic seizures in EL mice. Brain Res Mol Brain Res. 2004 Dec;132(1):13-17.

5. Yokoyama H, Onodera K, Maeyama K, Yanai K, Iinuma K, Tuomisto L, Watanabe T. Histamine levels and clonic convulsions of electrically-induced seizure in mice: the effects of fluoromethylhistidine and metoprine. Naunyn Schmiedebergs Arch Pharmacol.1992 July;346(1):40-45.

6. Fujii Y, Tanaka T, Harada C, Hirai T, Kamei C. Epileptogenic activity induced by histamine $\mathrm{H} 1$ antagonists in amygdala-kindled rats. Brain Res. 2003 Nov;991(12):258-61

7. Murphy K, Delanty N. Drug-induced seizures: general principles in assessment, management and prevention. CNS Drugs. 2000 Aug;14(2):135-46.

8. Ten Eick AP, Blumer JL, Reed MD. Safety of antihistamines in children. Drug Saf. 2001;24(2):119-47.

9. Kiviranta T, Tuomisto L, Airaksien EM. Histamine in cerebrospinal fluid of children with febrile convulsions. Epilepsia. 1995 Mar;36(3):276-80. 
10. Churchill JA, Gammon GD. The effect of antihistaminic drugs on convulsive seizures. J Am Med Assoc.1949 Sep;141(1):18-21.

11. Miyata I, Saegusa H, Sakurai M. Seizure-modifying potential of histamine $\mathrm{H} 1$ antagonists: A clinical observation. Pediatr Int. 2011 (Oct);53(5):706-08.
12. Takano T, Sakaue Y, Sokoda T, Akabori S, Maruo Y, Taga T, Ohno M, Takeuchi Y. Seizure susceptibility due to antihistamines in febrile seizures. Pediatr Neurol. 2010 Apr;42(4):277-79.

13. Kulkarni R, Valvi C, Kinikar A. Seizure susceptibility due to antihistamines in febrile seizures. Pediatr Neurol. 2010 Oct;43(4):303.

\section{How to cite this article?}

Patel U, Patel N, Jain R, Ratre B. Antihistaminic Induced Febrile Seizure - An Important association: a Case report. Int J Med Res Rev 2013;1(4):216-219 